\title{
Low-Dimensional Metal-Organic Coordination Structures on Graphene
}

\author{
Jun Li, $^{\dagger}$ Leonid Solianyk, $^{\dagger}$ Nico Schmidt, $^{\dagger}$ Brian Baker, $^{\dagger}$ Stefano Gottardi, $^{\dagger}$ \\ Juan Carlos Moreno Lopez, ${ }^{\dagger, \S}$ Mihaela Enache, ${ }^{\dagger}$ Leticia Monjas, ${ }^{\ddagger}$ Ramon van der Vlag, \\ Remco W. A. Havenith, ${ }^{\dagger,+, \# \odot ~ A n n a ~ K . ~ H . ~ H i r s c h, ~}{ }^{+, \|, \perp}$ and Meike Stöhr, ${ }^{*}{ }^{\dagger}$
}

'Zernike Institute for Advanced Materials, University of Groningen, Nijenborgh 4, 9747 AG Groningen, The Netherlands

${ }^{\ddagger}$ Stratingh Institute for Chemistry, University of Groningen, Nijenborgh 7, 9747 AG Groningen, The Netherlands

${ }^{\S}$ Faculty of Physics, University of Vienna, Strudlhofgasse 4, 1090 Vienna, Austria

"Helmholtz Institute for Pharmaceutical Research Saarland (HIPS) - Helmholtz Centre for Infection Research (HZI), Department of Drug Design and Optimization, Campus Building E8.1, 66123 Saarbrücken, Germany

${ }^{\perp}$ Department of Pharmacy, Saarland University, Campus Building E8.1, 66123 Saarbrücken, Germany

\#Ghent Quantum Chemistry Group, University of Ghent, 9000 Ghent, Belgium

Supporting Information

ABSTRACT: We report the formation of one- and two-dimensional metal-organic coordination structures from para-hexaphenyl-dicarbonitrile $\left(\mathrm{NC}-\mathrm{Ph}_{6}-\mathrm{CN}\right)$ molecules and $\mathrm{Cu}$ atoms on graphene epitaxially grown on $\operatorname{Ir}(111)$. By varying the stoichiometry between the $\mathrm{NC}-\mathrm{Ph}_{6}-\mathrm{CN}$ molecules and $\mathrm{Cu}$ atoms, the dimensionality of the metal-organic coordination structures could be tuned: for a 3:2 ratio, a two-dimensional hexagonal porous network based on threefold $\mathrm{Cu}$ coordination was observed, while for a 1:1 ratio, one-dimensional chains based on twofold $\mathrm{Cu}$ coordination were formed. The formation of metal-ligand bonds was supported by imaging the $\mathrm{Cu}$ atoms within the metal-organic coordination structures with scanning tunneling microscopy. Scanning tunneling spectroscopy measurements demonstrated that the electronic properties of $\mathrm{NC}-\mathrm{Ph}_{6}-\mathrm{CN}$ molecules and $\mathrm{Cu}$ atoms were different between the two-dimensional porous network and one-dimensional molecular chains.

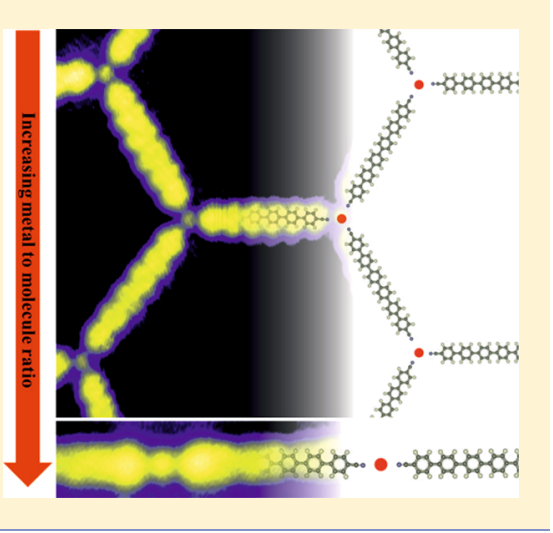

\section{INTRODUCTION}

Molecular self-assembly on graphene has attracted increasing attention over the past few years due to its potential for applications ranging from organic electronics over photovoltaics to spintronics. ${ }^{1-9}$ On the one hand, the chemical inertness and low density of states near the Fermi level make graphene a promising choice as a buffer layer to decouple adsorbed molecules as well as atoms from the underlying (metallic) substrate. Importantly, this holds the promise to preserve the intrinsic properties of the adsorbed species such as magnetic moments or catalytic activity. Besides, the low interaction between the absorbed species and graphene generally allows for real space investigation of the electronic properties of the molecules with scanning tunneling microscopy (STM). ${ }^{10,11}$ On the other hand, the molecular selfassembly on graphene can be also employed as a promising method to tune the electronic properties of graphene on a macroscopic scale. ${ }^{12,13}$ For this purpose, the molecule graphene interaction has to be stronger than a mere physisorptive one. According to theoretical studies, even an electronic band gap can be opened through the adsorption of carefully designed organic molecules on graphene. ${ }^{14}$ The key point in this case is the breaking of the sublattice symmetry of graphene by unequally transferring charge between the molecules and two graphene sublattices.

Despite the abundant knowledge present for two-dimensional (2D) (supra)molecular structures on metallic surfaces, ${ }^{15,16}$ only little has so far been used for either controllably tailoring graphene's properties via noncovalent chemical modification $^{17-22}$ or for preserving the intrinsic properties of the adsorbed species utilizing graphene's decoupling properties (vide supra). In particular, 2D metal-organic coordination networks (MOCNs) present an intensively investigated material class because of the possibility of controllably adjusting their electronic as well as magnetic properties through the constituent building blocks with the advantage of a relatively high stability for a supramolecular structure. ${ }^{23,24}$ Theoretical calculations have identified 2D MOCNs as a new class of organic topological insulators. ${ }^{25}$ However, their actual fabrication requires a noninteracting substrate, and graphene has been suggested as a promising possibility. ${ }^{26}$ On the other hand, 2D MOCNs have also been suggested for forming a

Received: January 11, 2019

Revised: April 26, 2019

Published: April 30, 2019 
heterostructure with graphene, thereby, the two 2D layers (graphene and MOCN) would mutually influence their electronic and magnetic properties, giving rise to new ones and not only to a combination of them. ${ }^{27}$

Here, we report a systematic study for the creation of lowdimensional MOCNs on graphene epitaxially grown on $\operatorname{Ir}(111)$ from para-hexaphenyl-dicarbonitrile $\left(\mathrm{NC}-\mathrm{Ph}_{6}-\mathrm{CN}\right)$ molecules (Figure 1c) and co-deposited $\mathrm{Cu}$ atoms. The as-
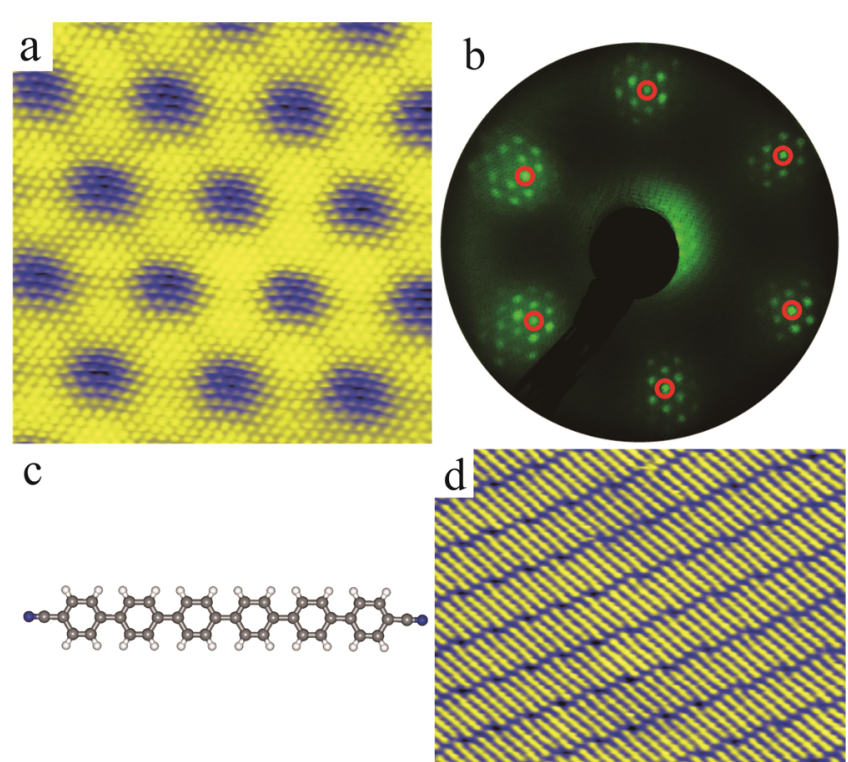

Figure 1. (a) STM image $(9 \mathrm{~nm} \times 9 \mathrm{~nm}, U=-0.5 \mathrm{~V}, I=120 \mathrm{pA}, T=$ $77 \mathrm{~K}$ ) of graphene grown on $\operatorname{Ir}(111)$ showing atomic resolution as well as the Moiré pattern. (b) LEED pattern of graphene epitaxially grown on $\operatorname{Ir}(111)$ taken at an energy of $138 \mathrm{eV}$. The first-order Ir spots are marked by red circles. The presence of the graphene Moire pattern can be identified by the satellite spots around the first-order Ir spots. (c) Chemical structure of the $\mathrm{NC}-\mathrm{Ph}_{6}-\mathrm{CN}$ molecule. Carbon atoms are gray, nitrogen atoms are blue, and hydrogen atoms are white. (d) STM image $(25 \mathrm{~nm} \times 19 \mathrm{~nm}, U=-0.5 \mathrm{~V}, I=20 \mathrm{pA}, T=$ $77 \mathrm{~K}$ ) of the as-deposited $\mathrm{NC}-\mathrm{Ph}_{6}-\mathrm{CN}$ molecules on graphene/ $\operatorname{Ir}(111)$. The molecules are arranged parallel to one another in a striped pattern.

deposited $\mathrm{NC}-\mathrm{Ph}_{6}-\mathrm{CN}$ molecules self-assembled on graphene/Ir(111) into a close-packed arrangement consisting of packed one-dimensional (1D) rows of molecules arranged in parallel, which appeared as a striped pattern. By co-adsorbing $\mathrm{Cu}$ atoms and varying the stoichiometry between the NC$\mathrm{Ph}_{6}-\mathrm{CN}$ molecules and $\mathrm{Cu}$ atoms, a basketweave-like pattern ( 6:1 ratio), a $2 \mathrm{D}$ hexagonal porous network (3:2 ratio), or 1D chains (1:1 ratio) were formed. The bright protrusions between the molecules observed on the STM images originate from the presence of the $\mathrm{Cu}$ atoms, which indicates the formation of metal-ligand bonding between the terminal cyano groups of the $\mathrm{NC}-\mathrm{Ph}_{6}-\mathrm{CN}$ molecules and the codeposited $\mathrm{Cu}$ atoms. The structural transformation of the metal-organic coordination structures in dependence of the number of $\mathrm{Cu}$ atoms with respect to organic molecules involves the modification of the electronic properties of both the $\mathrm{NC}-\mathrm{Ph}_{6}-\mathrm{CN}$ molecules and $\mathrm{Cu}$ atoms, as evidenced by scanning tunneling spectroscopy (STS) measurements.

\section{EXPERIMENTAL METHODS}

The experiments were carried out in a two-chamber ultrahigh vacuum system (base pressure of $4 \times 10^{-11} \mathrm{mbar}$ ) housing a commercial low-temperature STM (Scienta Omicron GmbH). The $\operatorname{Ir}(111)$ substrate was cleaned by repeated cycles of Argon ion sputtering followed by annealing at $1300 \mathrm{~K}$. Graphene was grown via chemical vapor deposition by exposing the $\operatorname{Ir}(111)$ substrate held at $1200 \mathrm{~K}$ to a partial pressure of $4 \times 10^{-7} \mathrm{mbar}$ of ethylene gas for $3 \mathrm{~min}$. The $\mathrm{NC}-\mathrm{Ph}_{6}-\mathrm{CN}$ molecules were heated to $550 \mathrm{~K}$ inside a commercial molecule evaporator (OmniVac) and deposited onto the graphene/ $\operatorname{Ir}(111)$ substrate held at room temperature. The $\mathrm{Cu}$ atoms were deposited with an electron beam evaporator (Oxford Applied Research Ltd.). The evaporation rate of both the molecules and $\mathrm{Cu}$ atoms was monitored with a water-cooled quartz crystal microbalance to precisely determine coverage. STM measurements were performed at both 77 and $4.5 \mathrm{~K}$ with a mechanically cut $\mathrm{Pt} / \mathrm{Ir}$ wire in constant current mode. All bias voltages are given with respect to a grounded tip. The STM images were processed with the WSxM software. ${ }^{28}$ STS measurements were performed at $4.5 \mathrm{~K}$ by using a lock-in amplifier [modulation amplitude of $10 \mathrm{mV}$ (rms) and frequency of $677 \mathrm{~Hz}$.

\section{RESULTS AND DISCUSSION}

After the growth of graphene on $\operatorname{Ir}(111)$, the quality of graphene was checked by STM and low-energy electron diffraction (LEED) measurements. The atomically resolved STM image (Figure 1a) shows the Moiré pattern originating from the lattice mismatch between graphene and $\operatorname{Ir}(111)$. In the LEED pattern (Figure 1b), the Moiré pattern can be discerned by the satellite spots around the first-order spots of $\operatorname{Ir}(111){ }^{29,30}$ Both experiments indicated the successful synthesis of graphene. Figure 1c shows the molecular structure of $\mathrm{NC}-\mathrm{Ph}_{6}-\mathrm{CN}$ : six phenyl rings are joined by single $\mathrm{C}-\mathrm{C}$ bonds with a terminal cyano group at each end of the molecule. MOCNs from the family of this molecule (NC$\mathrm{Ph}_{n}-\mathrm{CN}$ with $\left.n=3,4,5,6\right)$ have been extensively studied mainly on $\mathrm{Ag}(111)$ and $\mathrm{Cu}(111)$ surfaces. $^{31-35}$ Figure $1 \mathrm{~d}$ shows the close-packed arrangement of $\mathrm{NC}-\mathrm{Ph}_{6}-\mathrm{CN}$ after deposition on graphene $/ \operatorname{Ir}(111)$ held at room temperature. Individual $\mathrm{NC}-\mathrm{Ph}_{6}-\mathrm{CN}$ molecules can be easily recognized by their rod-like shape. Similar to the arrangement of NC$\mathrm{Ph}_{6}-\mathrm{CN}$ on $\mathrm{Ag}(111)$ for close-to-monolayer coverage, ${ }^{35}$ the molecules are arranged in a striped pattern on graphene/ $\operatorname{Ir}(111)$. Within one stripe, the molecules were parallel to one another, while for either every fourth or fifth molecule, a shift along the long axis of the molecule with a distance of about one phenyl ring occurred.

For our experiments, the molecular coverage was purposely kept below one monolayer to enable optimal MOCN assembly. Upon deposition of a very small amount of $\mathrm{Cu}$ atoms onto the close-packed arrangement of $\mathrm{NC}-\mathrm{Ph}_{6}-\mathrm{CN}$ on graphene/ $\operatorname{Ir}(111)$, the striped pattern transformed into a basketweave-like pattern (Figure $2 \mathrm{a}-\mathrm{c}$ ). Though the parallel arrangement of the molecules was still observed (marked by black lines in Figure 2a), some packages of parallel molecules were rotated by $60^{\circ}$ with respect to the other molecules. Moreover, some molecules were also arranged in a head-on configuration (marked by red lines in Figure 2a). In the headon configuration, the cyano groups of the involved molecules point directly toward each other. The electrostatic repulsion 


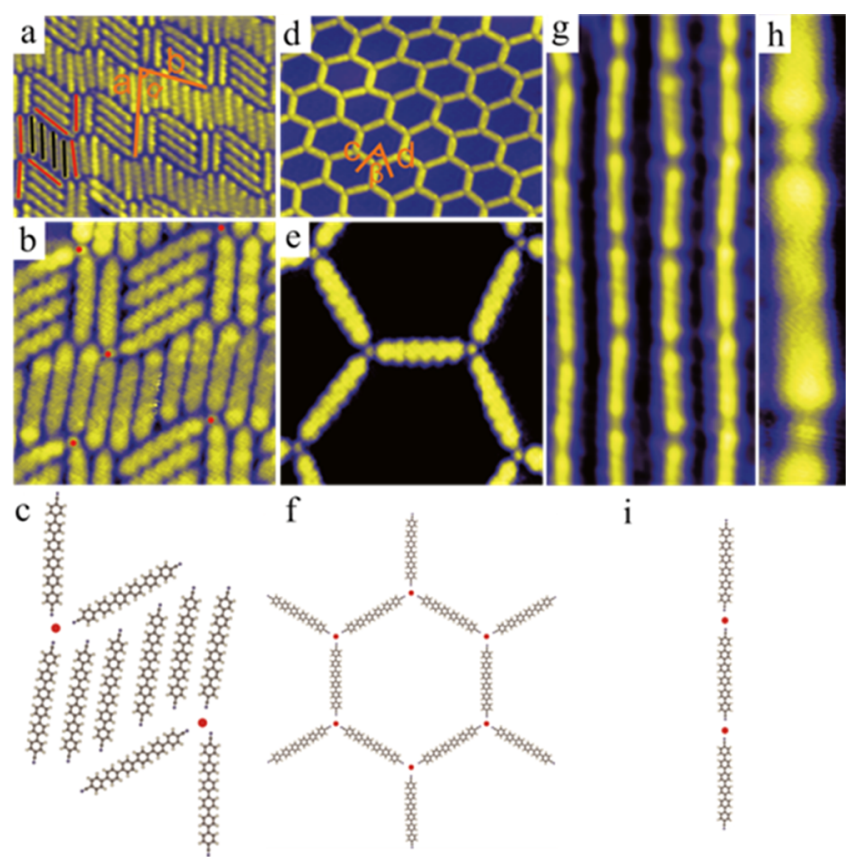

Figure 2. (a,d,g) STM images of the self-assembled molecular structures from $\mathrm{NC}-\mathrm{Ph}_{6}-\mathrm{CN}$ molecules and co-deposited $\mathrm{Cu}$ atoms at different molecule-to-atom ratios. Structural evolution of the MOCNs with decreasing molecule-to-atom ratio: the basketweavelike pattern (a), hexagonal porous network (d), and molecular chains (g). (b,e,h) Close-up STM images with intramolecular resolution of the basketweave-like pattern (b), hexagonal porous network (e), and molecular chains $(\mathrm{h})$. In all three STM images, the $\mathrm{Cu}$ atoms are clearly resolved as round protrusions between neighboring $\mathrm{NC}-\mathrm{Ph}_{6}-$ $\mathrm{CN}$ molecules, which reveals the formation of metal-ligand bonds. $(\mathrm{c}, \mathrm{f}, \mathrm{i})$ Molecular models of the basketweave-like pattern (c), hexagonal porous network (f), and molecular chain (i). The $\mathrm{Cu}$ atoms are depicted by red dots. Scanning parameters: (a) $17 \mathrm{~nm} \times 13$ $\mathrm{nm}, U=-0.5 \mathrm{~V}, I=20 \mathrm{pA}, T=77 \mathrm{~K}$; (b) $8 \mathrm{~nm} \times 8 \mathrm{~nm}, U=-0.5 \mathrm{~V}$, $I=20 \mathrm{pA}, T=77 \mathrm{~K}$; (d) $34.5 \mathrm{~nm} \times 26.4 \mathrm{~nm}, U=-1 \mathrm{~V}, I=20 \mathrm{pA}, T$ $=77 \mathrm{~K}$; (e) $8 \mathrm{~nm} \times 8 \mathrm{~nm}, U=-0.5 \mathrm{~V}, I=120 \mathrm{pA}, T=77 \mathrm{~K} ;(\mathrm{g}) 8$ $\mathrm{nm} \times 18 \mathrm{~nm}, U=-2 \mathrm{~V}, I=10 \mathrm{pA}, T=77 \mathrm{~K}$; and $(\mathrm{h}) 1.0 \mathrm{~nm} \times 5.5$ $\mathrm{nm}, U=1 \mathrm{~V}, I=10 \mathrm{pA}, T=4.5 \mathrm{~K}$.

between the partially negatively charged nitrogen atoms of the cyano groups would make this arrangement energetically unfavorable, unless metal-ligand bonding takes place between the cyano groups and deposited $\mathrm{Cu}$ atoms. To investigate this in more detail, a close-up STM image was taken (Figure 2b). The round bright protrusions (marked by red dots) can be tentatively assigned to the central $\mathrm{Cu}$ atoms of the metalligand bonds which were formed between three $\mathrm{NC}-\mathrm{Ph}_{6}-\mathrm{CN}$ molecules and one $\mathrm{Cu}$ atom (see Figure S2). It should be noted that for MOCNs on metal surfaces, the metal centers are rarely imaged by STM. ${ }^{36-38}$ This observation may be ascribed to the lack of electronic states at the metal centers around the Fermi level. For example, for two MOCNs from perylene derivatives on $\mathrm{Cu}(111)$ electronic states around $3 \mathrm{eV}$ above the Fermi level were identified. ${ }^{37,40}$ The protrusions resolved between three adjacent molecules provide a direct evidence of the threefold metal coordination formed between most likely one $\mathrm{Cu}$ atom and the cyano groups of three neighboring molecules. The proposed molecular model is shown in Figure 2c. Because of the threefold metal coordination bonding between the molecules and the $\mathrm{Cu}$ atoms, the molecules are arranged in a rhombic unit cell. In the cavity of the rhombus, the $\mathrm{NC}-\mathrm{Ph}_{6}-\mathrm{CN}$ molecules were packed in a side-to-side configuration. The unit cell of the basketweave-like pattern is marked in orange in Figure $2 a$, and the size of the unit cell is measured to be $a=5.6 \pm 0.2 \mathrm{~nm}, b=4.5 \pm 0.2 \mathrm{~nm}$, and $\alpha=77$ $\pm 3^{\circ}$.

The fact that some molecules were still arranged side-to-side indicates a deficiency of $\mathrm{Cu}$ atoms that made it impossible for the molecules to exclusively interact via metal coordination bonding. Therefore, a sample with a molecule-to- $\mathrm{Cu}$ atom ratio of 3:2 was prepared. As shown in Figure $2 \mathrm{~d}$, the hexagonal porous network became the dominant phase. It should be noted that the molecular networks appear distorted with respect to a perfect hexagonal symmetry, which most probably originates from the relatively weakly corrugated interaction potential between graphene and $\mathrm{NC}-\mathrm{Ph}_{6}-\mathrm{CN}$. An STM image with intramolecular resolution was taken to gain insight into the bonding of the hexagonal porous network (Figure 2e). The six phenyl rings of the $\mathrm{NC}-\mathrm{Ph}_{6}-\mathrm{CN}$ molecules and $\mathrm{Cu}$ atoms are clearly resolved, which demonstrates that the hexagonal porous network formed on graphene/ $\operatorname{Ir}(111)$ was stabilized by threefold metal coordination between the deposited $\mathrm{Cu}$ atoms and the cyano groups of the molecules. The unit cell of the hexagonal porous network is marked in orange in Figure $2 \mathrm{~d}$, and the size of the unit cell is measured to be $c=d=5.7 \pm 0.2 \mathrm{~nm}$, and $\beta=60 \pm 2^{\circ}$. Figure $2 \mathrm{f}$ displays the molecular model for the hexagonal porous network structure. Samples with a $\mathrm{Cu}$ atom to molecule ratio of $1: 1$ were also prepared to investigate the self-assemblies at an even higher ratio. As can be seen in Figure $2 \mathrm{~g}$, the $1 \mathrm{D}$ molecular chains now were the dominant phase of the molecular self-assembly. A detailed STM image of an individual molecular chain was acquired at $4.5 \mathrm{~K}$ (Figure $2 \mathrm{~h}$ ) because the mobility of individual chains prevented stable imaging conditions at $77 \mathrm{~K}$. The chain segment length amounts to $3.3 \pm 0.1 \mathrm{~nm}$, which is considerably larger than the theoretical $\mathrm{NC}-\mathrm{Ph}_{6}-\mathrm{CN}$ molecule length of $2.96 \mathrm{~nm}$. This results in a $\mathrm{N}-\mathrm{Cu}$ coordination bonding length of around $0.17 \mathrm{~nm}$, which fits well with previous studies. ${ }^{31,33,39}$ The bright protrusions, which are clearly discernible between two adjacent molecules within the molecular chain, can be again assigned to $\mathrm{Cu}$ atoms demonstrating that the molecular chains are stabilized by metal coordination. This assignment is also based on simulated STM data (Figure S2). The structural model is depicted in Figure 2i. Therefore, by decreasing the molecule-to- $\mathrm{Cu}$ atom ratio, we were able to transform the structural arrangement of the molecular self-assembly from a basketweave-like pattern to a $2 \mathrm{D}$ porous network and finally to 1D molecular chains. The corresponding intermolecular interactions concurrently changed from threefold to twofold metal coordination. The transformation of the structural molecular arrangement is an indication of the flexibility and versatility of the coordination bonding between the $\mathrm{Cu}$ atoms and cyano groups, which is in line with previous research results. $^{33,41}$

The possibility to clearly image the $\mathrm{Cu}$ atoms within the metal-organic coordination structures with STM deserves additional attention. For the metal atom centers within 2D MOCNs adsorbed on metallic surfaces it has been reported that they can be imaged by STM only under certain conditions, for example, at very high bias voltages. ${ }^{36-38,40}$ However, in the current study, the $\mathrm{Cu}$ atoms were observed for various samples with different tips (and thus, tip conditions) and different scanning parameters. Therefore, we propose that 
the observation of the $\mathrm{Cu}$ atoms in the current study does not stem from a special tip condition but from the weak interaction between the $\mathrm{Cu}$ atoms and underlying graphene.

By adjusting the molecule-to- $\mathrm{Cu}$ atom ratio, the type of coordination bonding (threefold vs twofold) can be selected and consequently, the type of metal-organic coordination structures formed can be tuned. Therefore, these two structures represent a unique model system to investigate the modification of the electronic properties of both the ligand molecule and the coordinating metal atom when the bonding motif is changed. The red curve in Figure 3a shows the STS

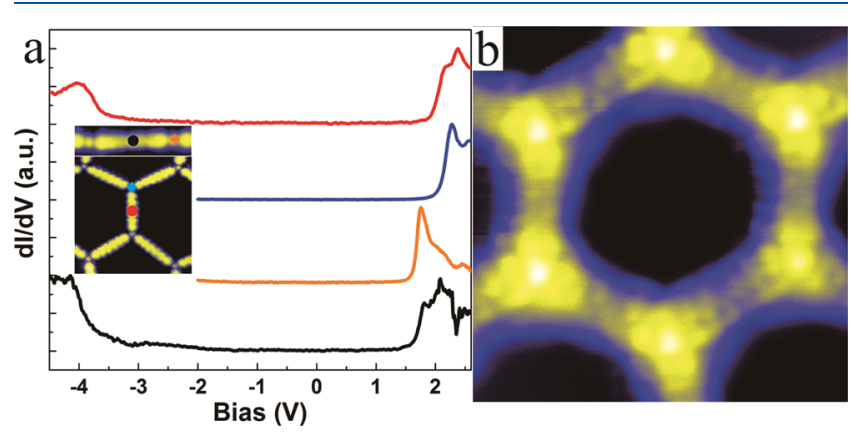

Figure 3. (a) Comparison of STS spectra taken at different positions on the molecular chains and the porous network, respectively. Black curve: STS on a molecule in the molecular chain. The position is marked in black in the uppermost inset. Orange curve: STS on a $\mathrm{Cu}$ atom in the molecular chain. The position is marked in orange in the uppermost inset. Blue curve: STS on a $\mathrm{Cu}$ atom coordinating the porous network. The position is marked in blue in the inset. Red curve: STS on a molecule in the porous network. The position is marked in red in the inset. (b) Detailed STM image of an individual pore of the porous network taken at a bias equal to the LUMO position for resolving the molecular orbitals in real space. Scanning parameters: (b) $8 \mathrm{~nm} \times 8 \mathrm{~nm}, U=2.4 \mathrm{~V}, I=350 \mathrm{pA}, T=4.5 \mathrm{~K}$.

spectrum acquired on a molecule of the porous network (position marked by a red sphere in the inset). Two peaks are clearly visible at energies of -4.0 and $+2.4 \mathrm{eV}$ with a broad gap between them. On the basis of the interpretation that the $\mathrm{dI} /$ $\mathrm{d} V$ signal can be considered proportional to the local density of states and that tunneling into/out of molecular orbitals can lead to peaks in $\mathrm{d} I / \mathrm{d} V$ spectra, ${ }^{42}$ we assign the peaks to the highest occupied molecular orbital (HOMO) and lowest unoccupied molecular orbital (LUMO), respectively. This results then in a band gap of $6.4 \mathrm{eV}$. It should be noted that because our system can be viewed as a double barrier tunneling junction the STS data will not provide the exact HOMO/ LUMO positions and thus, also not the right band gap. ${ }^{43,44}$ For the molecules in the molecular chains, the HOMO and LUMO was found at -4.2 and $+2.1 \mathrm{eV}$, respectively, giving a band gap of $6.3 \mathrm{eV}$ (see the black curve in Figure $3 \mathrm{a}$ and location of the STS spectra taken in the uppermost inset). While the band gap is nearly the same for the two cases, a shift of the spectral features for the twofold coordinated chains compared with the threefold coordinated porous network is already obvious by a visual inspection of the spectra shown in Figure 3a. On the basis of earlier reports describing changes of molecular states due to bonding of the molecules to metal atoms, ${ }^{45-49}$ we assign the observed spectral changes to changes in the metal coordination; that is, if a twofold or a threefold metal coordination is present. It should be noted that a band gap of around $7.7 \mathrm{eV}$ was determined for $\mathrm{NC}-\mathrm{Ph}_{6}-\mathrm{CN}$ adsorbed on multilayer graphene in the close-packed striped pattern. ${ }^{54}$ Moreover, the clearly resolved $\mathrm{Cu}$ atoms in the STM images enabled us to unambiguously perform STS measurements directly on top of the $\mathrm{Cu}$ atoms. Thereby, we could probe the electronic properties of the $\mathrm{Cu}$ atoms and whether the type of metal coordination also influenced them. For the $\mathrm{Cu}$ atoms in the porous network, a clear peak is present at $+2.3 \mathrm{eV}$ (blue curve in Figure $3 \mathrm{a}$ ). In contrast, the peak shifts to $+1.8 \mathrm{eV}$ for the $\mathrm{Cu}$ atoms in the molecular chains (orange curve in Figure $3 a$ ). The observed changes of the electronic properties of the coordinated $\mathrm{Cu}$ atoms in the porous network compared with the chains are in agreement with the shift of the molecular orbitals of the $\mathrm{NC}-\mathrm{Ph}_{6}-\mathrm{CN}$ molecules. This demonstrates that the change in bonding configuration has a significant influence on the electronic properties of the constituents (see also Figure S1). For getting more insight into the molecule$\mathrm{Cu}$ atom interaction, we focus on the onset of the unoccupied electronic states. For the chains, the onset is practically at the same position for the $\mathrm{Cu}$ atoms compared with the molecules while only the peak structure varies. This alignment of the electronic state of the $\mathrm{Cu}$ atoms with the one for the $\mathrm{NC}-$ $\mathrm{Ph}_{6}-\mathrm{CN}$ molecules is indicative of a chemical bonding between the molecules and the $\mathrm{Cu}$ atoms. ${ }^{50,51}$ Turning to the porous network, a similar alignment of the unoccupied electronic states of the $\mathrm{Cu}$ atoms and the $\mathrm{NC}-\mathrm{Ph}_{6}-\mathrm{CN}$ molecules was observed in the STS spectra. However, the LUMO of the molecule appeared at a slightly lower energy than the electronic state of the $\mathrm{Cu}$ atoms. Also for this case, we conclude that chemical bonding took place between the $\mathrm{Cu}$ atoms and molecules. To spatially investigate the electronic structure of the porous network, an STM image was taken at $+2.4 \mathrm{eV}$ (LUMO of the molecules). As can be seen in Figure $3 \mathrm{~b}$, this orbital is distributed over the $\mathrm{NC}-\mathrm{Ph}_{6}-\mathrm{CN}$ molecules as well as the $\mathrm{Cu}$ atoms with more contrast at and around the $\mathrm{Cu}$ atoms.

Compared with the extensive research for $2 \mathrm{D}$ MOCNs adsorbed on metal surfaces, their fabrication and investigation on graphene has up to now hardly been reported. ${ }^{52} 2 \mathrm{D}$ MOCNs on graphene are potentially interesting for different reasons. For adsorbed atoms and molecules, the presence of graphene is likely to decouple them from the underlying metal substrate. This is reflected in the relatively narrow resonances in the STS spectra, especially on the side of the unoccupied states (see Figure 3a). ${ }^{53}$ Compared with 2D MOCNs on metal substrates, graphene is generally not able to take the role as a coordinating ligand, that is, it does not hybridize with the metal atoms and consequently, a different coordination geometry is obtained. Furthermore, the decoupling effect of graphene may preserve the magnetic moments, catalytic activity, and further properties of the adsorbed species, ultimately resulting in new phenomena such as topological insulators.

\section{CONCLUSIONS}

We performed an experimental study on the formation of MOCNs on graphene from $\mathrm{NC}-\mathrm{Ph}_{6}-\mathrm{CN}$ molecules and $\mathrm{Cu}$ atoms. By adjusting the ratio between molecules and $\mathrm{Cu}$ atoms, different kinds of metal-organic coordination structures could be formed, namely, a basketweave-like pattern, a hexagonal porous network and $1 \mathrm{D}$ molecular chains while the former two exhibit threefold metal coordination and the latter one exhibits twofold metal coordination. The electronic properties of both the $\mathrm{NC}-\mathrm{Ph}_{6}-\mathrm{CN}$ molecules and $\mathrm{Cu}$ 
atoms were modified in dependence of the bonding motif present for the different structures. The presence of graphene enabled the decoupling of the metal-organic coordination structures from the metallic substrate, resulting in the imaging of the $\mathrm{Cu}$ atoms and obtaining intramolecular contrast as well as investigating their electronic properties. In this respect, graphene seems to be a promising candidate for decoupling molecules from metal substrates, similar to the established usage of thin insulating layers like $\mathrm{NaCl}$. On the other hand, MOCNs hold the promise to be employed for tuning the electronic or magnetic properties of graphene, especially in the form of heterostructures.

\section{ASSOCIATED CONTENT}

\section{S Supporting Information}

The Supporting Information is available free of charge on the ACS Publications website at DOI: 10.1021/acs.jpcc.9b00326.

Additional experimental and simulated STM data of $\mathrm{NC}-\mathrm{Ph}_{6}-\mathrm{CN}$ molecules on graphene (PDF).

\section{AUTHOR INFORMATION}

\section{Corresponding Author}

*E-mail: m.a.stohr@rug.nl. Phone: +31 503634438.

\section{ORCID}

Ramon van der Vlag: 0000-0002-8796-2792

Remco W. A. Havenith: 0000-0003-0038-6030

Meike Stöhr: 0000-0002-1478-6118

Notes

The authors declare no competing financial interest.

\section{ACKNOWLEDGMENTS}

This work was supported by the Foundation for Fundamental Research on Matter (FOM), part of the Netherlands Organisation for Scientific Research (NWO), by NWO (Vidi grant 723.014.008), by the European Research Council (ERC2012-StG 307760-SURFPRO), and by the Zernike Institute for Advanced Materials of the University of Groningen.

\section{REFERENCES}

(1) Pang, S.; Hernandez, Y.; Feng, X.; Müllen, K. Graphene as Transparent Electrode Material for Organic Electronics. Adv. Mater. 2011, 23, 2779-2795.

(2) Wang, X.; Zhi, L.; Müllen, K. Transparent, Conductive Graphene Electrodes for Dye-Sensitized Solar Cells. Nano Lett. 2008, 8, 323-327.

(3) Candini, A.; Klyatskaya, S.; Ruben, M.; Wernsdorfer, W.; Affronte, M. Graphene Spintronic Devices with Molecular Nanomagnets. Nano Lett. 2011, 11, 2634-2639.

(4) Hong, G.; Wu, Q.-H.; Ren, J.; Wang, C.; Zhang, W.; Lee, S.-T. Recent progress in organic molecule/graphene interfaces. Nano Today 2013, 8, 388-402.

(5) Macleod, J. M.; Rosei, F. Molecular Self-Assembly on Graphene. Small 2013, 10, 1038-1049.

(6) Kim, Y.-J.; Kim, Y.; Novoselov, K.; Hong, B. H. Engineering electrical properties of graphene: chemical approaches. 2D Mater. 2015, 2, 042001.

(7) Garnica, M.; Stradi, D.; Barja, S.; Calleja, F.; Díaz, C.; Alcamí, M.; Martín, N.; Vázquez de Parga, A. L.; Miranda, R.; Miranda, R. Long-range magnetic order in a purely organic $2 \mathrm{D}$ layer adsorbed on epitaxial graphene. Nat. Phys. 2013, 9, 368-374.

(8) Ciesielski, A.; Samorì, P. Supramolecular Approaches to Graphene: From Self-Assembly to Molecule-Assisted Liquid-Phase Exfoliation. Adv. Mater. 2016, 28, 6030-6051.
(9) Tang, Q.; Zhou, Z.; Chen, Z. Graphene-Related Nanomaterials: Tuning Properties by Functionalization. Nanoscale 2013, 5, 45414583.

(10) Martínez-Galera, A. J.; Nicoara, N.; Martínez, J. I.; Dappe, Y. J.; Ortega, J.; Gómez-Rodríguez, J. M. Imaging Molecular Orbitals of PTCDA on Graphene on Pt(111): Electronic Structure by STM and First-Principles Calculations. J. Phys. Chem. C 2014, 118, 1278212788.

(11) Järvinen, P.; Hämäläinen, S. K.; Ijäs, M.; Harju, A.; Liljeroth, P. Self-Assembly and Orbital Imaging of Metal Phthalocyanines on a Graphene Model Surface. J. Phys. Chem. C 2014, 118, 13320-13325.

(12) Medina, H.; Lin, Y.-C.; Obergfell, D.; Chiu, P.-W. Tuning of Charge Densities in Graphene by Molecule Doping. Adv. Funct. Mater. 2011, 21, 2687-2692.

(13) Tadich, A.; Edmonds, M. T.; Ley, L.; Fromm, F.; Smets, Y.; Mazej, Z.; Riley, J.; Pakes, C. I.; Seyller, T.; Wanke, M. Tuning the Charge Carriers in Epitaxial Graphene on $\mathrm{SiC}(0001)$ from Electron to Hole via Molecular Doping with $\mathrm{C}_{60} \mathrm{~F}_{48}$. Appl. Phys. Lett. 2013, 102, 241601.

(14) Shayeganfar, F.; Rochefort, A. Electronic Properties of SelfAssembled Trimesic Acid Monolayer on Graphene. Langmuir 2014, 30, 9707-9716.

(15) Barth, J. V. Molecular Architectonic on Metal Surfaces. Annu. Rev. Phys. Chem. 2007, 58, 375-407.

(16) Becker, C.; Wandelt, K. Templates in Chemistry III. In Topics in Current Chemistry; Broekmann, P., Dötz, K. H., Schalley, C. A., Eds.; Springer: Berlin, 2008.

(17) Wang, Q. H.; Hersam, M. C. Room-Temperature MolecularResolution Characterization of Self-Assembled Organic Monolayers on Epitaxial Graphene. Nat. Chem. 2009, 1, 206-211.

(18) Tsai, H.-Z.; Omrani, A. A.; Coh, S.; Oh, H.; Wickenburg, S.; Son, Y.-W.; Wong, D.; Riss, A.; Jung, H. S.; Nguyen, G. D.; Rodgers, G. F.; Aikawa, A. S.; Taniguchi, T.; Watanabe, K.; Zettl, A.; Louie, S. G.; Lu, J.; Cohen, M. L.; Crommie, M. F. Molecular Self-Assembly in a Poorly Screened Environment: $\mathrm{F}_{4} \mathrm{TCNQ}$ on Graphene/BN. ACS Nano 2015, 9, 12168-12173.

(19) Lu, J.; Yeo, P. S. E.; Zheng, Y.; Yang, Z.; Bao, Q.; Gan, C. K.; Loh, K. P. Using the Graphene Moire Pattern for the Trapping of C60 and Homoepitaxy of Graphene. ACS Nano 2012, 6, 944-950.

(20) Mao, J.; Zhang, H.; Jiang, Y.; Pan, Y.; Gao, M.; Xiao, W.; Gao, H.-J. Tunability of Supramolecular Kagome Lattices of Magnetic Phthalocyanines Using Graphene-Based Moiré Patterns as Templates. J. Am. Chem. Soc. 2009, 131, 14136-14137.

(21) Banerjee, K.; Kumar, A.; Canova, F. F.; Kezilebieke, S.; Foster, A. S.; Liljeroth, P. Flexible Self-Assembled Molecular Templates on Graphene. J. Phys. Chem. C 2016, 120, 8772-8780.

(22) Li, J.; Gottardi, S.; Solianyk, L.; Moreno-López, J. C.; Stöhr, M. 1,3,5-Benzenetribenzoic Acid on $\mathrm{Cu}(111)$ and Graphene/ $\mathrm{Cu}(111)$ : A Comparative STM Study. J. Phys. Chem. C 2016, 120, 18093-18098.

(23) Stepanow, S.; Lin, N.; Barth, J. V. Modular assembly of lowdimensional coordination architectures on metal surfaces. J. Phys.: Condens. Matter 2008, 20, 184002.

(24) Dong, L.; Gao, Z. A.; Lin, N. Self-assembly of metal-organic coordination structures on surfaces. Prog. Surf. Sci. 2016, 91, 101135.

(25) Wang, Z. F.; Liu, Z.; Liu, F. Organic Topological Insulators in Organometallic Lattices. Nat. Commun. 2013, 4, 1471.

(26) Wang, Z. F.; Liu, Z.; Liu, F. Quantum Anomalous Hall Effect in 2D Organic Topological Insulators. Phys. Rev. Lett. 2013, 110, 196801.

(27) Zhou, J. Stacking Interactions of Nickel Bis(dithiolene) with Graphene and beyond. RSC Adv. 2014, 4, 13361-13366.

(28) Horcas, I.; Fernández, R.; Gómez-Rodríguez, J. M.; Colchero, J.; Gómez-Herrero, J.; Baro, A. M. WSXM: A software for scanning probe microscopy and a tool for nanotechnology. Rev. Sci. Instrum. 2007, 78, 013705.

(29) N’Diaye, A. T.; Bleikamp, S.; Feibelman, P. J.; Michely, T. Two-Dimensional Ir Cluster Lattice on a Graphene Moiré on $\operatorname{Ir}(111)$. Phys. Rev. Lett. 2006, 97, 215501. 
(30) N’Diaye, A. T.; Coraux, J.; Plasa, T. N.; Busse, C.; Michely, T. Structure of Epitaxial Graphene on $\operatorname{Ir}(111)$. New J. Phys. 2008, 10, 043033.

(31) Kühne, D.; Klappenberger, F.; Decker, R.; Schlickum, U.; Brune, H.; Klyatskaya, S.; Ruben, M.; Barth, J. V. High-Quality 2D Metal-Organic Coordination Network Providing Giant Cavities within Mesoscale Domains. J. Am. Chem. Soc. 2009, 131, 3881-3883.

(32) Klappenberger, F.; Kühne, D.; Krenner, W.; Silanes, I.; Arnau, A.; García De, F. J.; Klyatskaya, S.; Ruben, M.; Barth, J. V.; Barth, J. V. Dichotomous Array of Chiral Quantum Corrals by a Self-Assembled Nanoporous Kagomé Network. Nano Lett. 2009, 9, 3509-3514.

(33) Pacchioni, G. E.; Pivetta, M.; Brune, H. Competing Interactions in the Self-Assembly of NC-Ph3-CN Molecules on $\mathrm{Cu}(111)$. J. Phys. Chem. C 2015, 119, 25442-25448.

(34) Schlickum, U.; Decker, R.; Klappenberger, F.; Zoppellaro, G.; Klyatskaya, S.; Ruben, M.; Silanes, I.; Arnau, A.; Kern, K.; Brune, H.; et al. Metal-Organic Honeycomb Nanomeshes with Tunable Cavity Size. Nano Lett. 2007, 7, 3813-3817.

(35) Kühne, D.; Klappenberger, F.; Decker, R.; Schlickum, U.; Brune, H.; Klyatskaya, S.; Ruben, M.; Barth, J. V. Self-Assembly of Nanoporous Chiral Networks with Varying Symmetry from Sexiphenyl-dicarbonitrile on $\operatorname{Ag}(111)$. J. Phys. Chem. C 2009, 113, 17851-17859.

(36) Bebensee, F.; Svane, K.; Bombis, C.; Masini, F.; Klyatskaya, S.; Besenbacher, F.; Ruben, M.; Hammer, B.; Linderoth, T. R. A Surface Coordination Network Based on Copper Adatom Trimers. Angew. Chem., Int. Ed. 2014, 53, 12955-12959.

(37) Björk, J.; Matena, M.; Dyer, M. S.; Enache, M.; Lobo-Checa, J.; Gade, L. H.; Jung, T. A.; Stöhr, M.; Persson, M. STM fingerprint of molecule-adatom interactions in a self-assembled metal-organic surface coordination network on $\mathrm{Cu}(111)$. Phys. Chem. Chem. Phys. 2010, 12, 8815-8821.

(38) Matena, M.; Stöhr, M.; Riehm, T.; Björk, J.; Martens, S.; Dyer, M. S.; Persson, M.; Lobo-Checa, J.; Müller, K.; Enache, M.; Wadepohl, H.; Zegenhagen, J.; Jung, T. A.; Gade, L. H. Aggregation and Contingent Metal/Surface Reactivity of 1,3,8,10-Tetraazaperopyrene (TAPP) on $\mathrm{Cu}(111)$. Chem.-Eur. J. 2010, 16, 2079-2091.

(39) Tait, S. L.; Langner, A.; Lin, N.; Stepanow, S.; Rajadurai, C.; Ruben, M.; Kern, K. One-Dimensional Self-Assembled Molecular Chains on $\mathrm{Cu}(100)$ : Interplay between Surface-Assisted Coordination Chemistry and Substrate Commensurability. J. Phys. Chem. C 2007, 111, 10982-10987.

(40) Matena, M.; Björk, J.; Wahl, M.; Lee, T.; Zegenhagen, J.; Gade, L. H.; Jung, T. A.; Persson, M.; Stöhr, M. On-Surface Synthesis of a Two-Dimensional Porous Coordination Network: Unraveling Adsorbate Interactions. Phys. Rev. B: Condens. Matter Mater. Phys. 2014, 90, 125408 .

(41) Pivetta, M.; Pacchioni, G. E.; Fernandes, E.; Brune, H. Temperature-dependent self-assembly of NC-Ph5-CN molecules on $\mathrm{Cu}(111)$. J. Chem. Phys. 2015, 142, 101928.

(42) Repp, J.; Meyer, G.; Stojković, S. M.; Gourdon, A.; Joachim, C. Molecules on Insulating Films: Scanning-Tunneling Microscopy Imaging of Individual Molecular Orbitals. Phys. Rev. Lett. 2005, 94, 026803 .

(43) Nazin, G. V.; Qiu, X. H.; Ho, W. Charging and Interaction of Individual Impurities in a Monolayer Organic Crystal. Phys. Rev. Lett. 2005, 95, 166103.

(44) Järvinen, P.; Hämäläinen, S. K.; Ijäs, M.; Harju, A.; Liljeroth, P. Self-Assembly and Orbital Imaging of Metal Phthalocyanines on a Graphene Model Surface. J. Phys. Chem. C 2014, 118, 13320-13325.

(45) Repp, J.; Meyer, G.; Paavilainen, S.; Olsson, F. E.; Persson, M. Imaging Bond Formation Between a Gold Atom and Pentacene on an Insulating Surface. Science 2006, 312, 1196-1199.

(46) Wegner, D.; Yamachika, R.; Zhang, X.; Wang, Y.; Baruah, T.; Pederson, M. R.; Bartlett, B. M.; Long, J. R.; Crommie, M. F. Tuning Molecule-Mediated Spin Coupling in Bottom-Up Fabricated Vanadium-Tetracyanoethylene Nanostructures. Phys. Rev. Lett. 2009, 103, 087205 .
(47) Nazin, G. V.; Qiu, X. H.; Ho, W. Visualization and Spectroscopy of a Metal-Molecule-Metal Bridge. Science 2003, 302, $77-81$.

(48) Wang, W.; Shi, X.; Lin, C.; Zhang, R. Q.; Minot, C.; Hove, M. A. V.; Hong, Y.; Tang, B. Z.; Lin, N. Manipulating Localized Molecular Orbitals by Single-Atom Contacts. Phys. Rev. Lett. 2010, $105,126801$.

(49) Wang, W.; Shi, X.; Wang, S.; Liu, J.; Hove, M. A. V.; Liu, P. N.; Zhang, R.-Q.; Lin, N. Cooperative Modulation of Electronic Structures of Aromatic Molecules Coupled to Multiple Metal Contacts. Phys. Rev. Lett. 2013, 110, 046802.

(50) Liljeroth, P.; Swart, I.; Paavilainen, S.; Repp, J.; Meyer, G. Single-Molecule Synthesis and Characterization of Metal-Ligand Complexes by Low-Temperature STM. Nano Lett. 2010, 10, 24752479.

(51) Albrecht, F.; Neu, M.; Quest, C.; Swart, I.; Repp, J. Formation and Characterization of a Molecule-Metal-Molecule Bridge in Real Space. J. Am. Chem. Soc. 2013, 135, 9200-9203.

(52) Kumar, A.; Banerjee, K.; Foster, A. S.; Liljeroth, P. TwoDimensional Band Structure in Honeycomb Metal-Organic Frameworks. Nano Lett. 2018, 18, 5596-5602.

(53) Urgel, J. I.; Schwarz, M.; Garnica, M.; Stassen, D.; Bonifazi, D.; Ecija, D.; Barth, J. V.; Auwärter, W. Controlling Coordination Reactions and Assembly on a $\mathrm{Cu}(111)$ Supported Boron Nitride Monolayer. J. Am. Chem. Soc. 2015, 137, 2420-2423.

(54) Schmidt, N.; Li, J.; Gottardi, S.; Moreno-Lopez, J. C.; Enache, M.; Monjas, L.; van der Vlag, R.; Havenith, R. W. A.; Hirsch, A. K. H.; Stöhr, M. Comparing the Self-Assembly of Sexiphenyl-Dicarbonitrile on Graphite and Graphene on $\mathrm{Cu}(111)$. Chem.-Eur. J. 2019, 25, 5065. 